Jurnal Pemberdayaan: Publikasi Hasil Pengabdian kepada Masyarakat

Vol. 2, No. 1, April 2018, Hal. 127-134

ISSN: 2088 4559; e-ISSN: XXXX-XXXX

DOI:

\title{
PEMBERDAYAAN MASYARAKAT COKRODININGRATAN, JETIS, YOGYAKARTA DALAM PROGRAM MASYARAKAT SEHAT
}

\author{
Iis Wahyuningsih ${ }^{1}$, Jenny Ilyas ${ }^{2}$, Ikhsan Jaya Guntur Wicaksono ${ }^{3}$ \\ ${ }^{1,2,3}$ Universitas Ahmad Dahlan, Kampus 3,Jl. Prof. Dr. Supomo, Janturan, Yogyakarta \\ Email: iis.wahyuningsih@pharm.uad.ac.id
}

\begin{abstract}
ABSTRAK
Permasalahan umum yang terdapat di kelurahan Cokrodiningratan adalah kurangnya implementasi kegiatan yang bertujuan menciptakan hidup sehat pada warganya. Maka program Kuliah Kerja Nyata (KKN) Universitas Ahmad Dahlan periode 57 ini difokuskan pada pengelolaan tentang lingkungan dan kesehatan. Program ini bertujuan memberdayakan masyarakat Cokrodiningratan dalam progam masyarakat ehat. Metode pelaksanaan program KKN meliputi: pendidikan masyarakat, difusi teknologi dan praktek langsung. Dampak dari kegiatan KKN ini adalah: 1) tercipta kesadaran masyarakat sasaran tentang menanam tanaman obat keluarga; 2) peningkatan ketrampilan masyarakat dalam membuat lilin aroma terapi dan balsem; 3) terciptanya kegiatan olah raga masyarakat secara rutin; 4) peningkatan pengetahuan masyarakat tentang obat ; 5) memperoleh layanan pengobatan gratis, 6) peningkatan kegiatan kebersihan lingkungan (kerja bakti).
\end{abstract}

Kata kunci: Pemberdayaan, Cokrodiningratan, Sehat,

\begin{abstract}
Common problems that occured in the village Cokrodiningratan is the lack of implementation of activities aimed at creating healthy living on its citizens. Because of that, the real work Kuliah Kerja Nyata (KKN) Ahmad Dahlan University 57 period is focused on the management of the environment and health. This program aims at empowering communities Cokrodiningratan in society health program. The method of implementation of the program of KKN include: community education, diffusion of technology and practice. The impact of the activities of the KKN is: 1) creating public awareness about the target plant medicinal plants of the family; 2) improvement of the skills of the community in making candles the aroma therapy and balm; 3) creation of community sports activities on a regular basis; 4) increased public knowledge about the drugs; 5) getting free treatment services, 6) improvement of environmental hygiene activities (work service).
\end{abstract}

Keywords: Empowerment, Cokrodiningratan, Healthy 


\section{PENDAHULUAN}

Cokrodiningratan adalah salah satu kelurahan di Kecamatan Jetis Kota Yogyakarta. Jumlah penduduk di Cokrodiningratan sebanyak 8.929 penduduk, yang terdiri dari 4.321 penduduk laki-laki dan 4.608 penduduk perempuan. Jumlah kepala keluarga di Cokrodiningratan sebanyak 2.909 kepala keluarga. Komposisi penduduk Cokrodiningratan berdasar agama yaitu agama Islam sebanyak 6.710 jiwa, Kristen 1.023 jiwa, Katholik sebanyak 1.109 jiwa, Hindu sebanyak 12 jiwa, Budha sebanyak 67 jiwa, dan Konghucu sebanyak 8 jiwa. Komposisi penduduk berdasarkan agama dan persentasinya dapat dilihat Gambar 1.

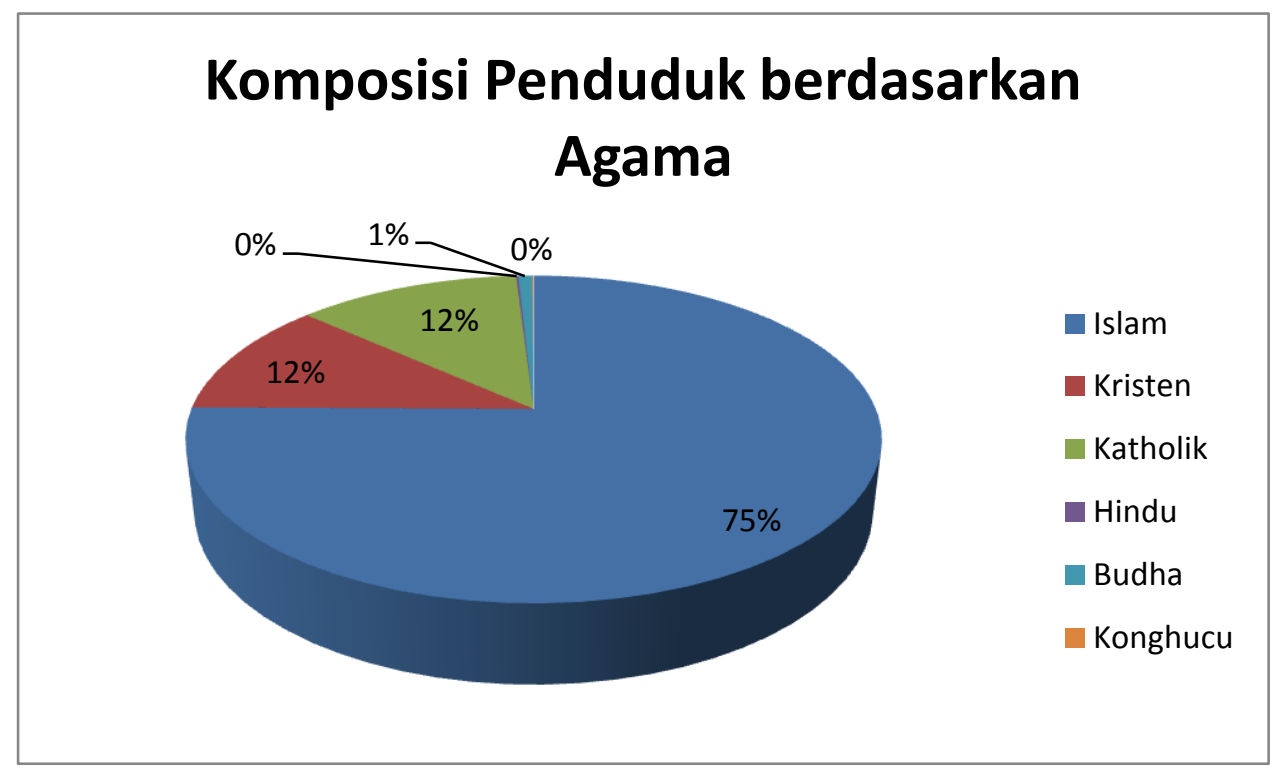

Gambar 1. Komposisi penduduk Cokrodiningratan berdasarkan agama

Berdasarkan informasi pada web statistika kependudukan DIY, komposisi penduduk Cokrodiningratan berdasar mata pencaharian yaitu pensiunan sebanyak 183 jiwa, TNI sebanyak 25 jiwa, POLRI sebanyak 3 jiwa, buruh sebanyak 397 jiwa, Pertanian/peternakan/perikanan sebanyak 2 jiwa, Karyawan/BUMN/BUMD sebanyak 31 jiwa, dan karyawan swasta sebanyak 1902. Komposisi penduduk berdasarkan mata pencaharian dan persentasinya dapat dilihat dalam gambar 2. 


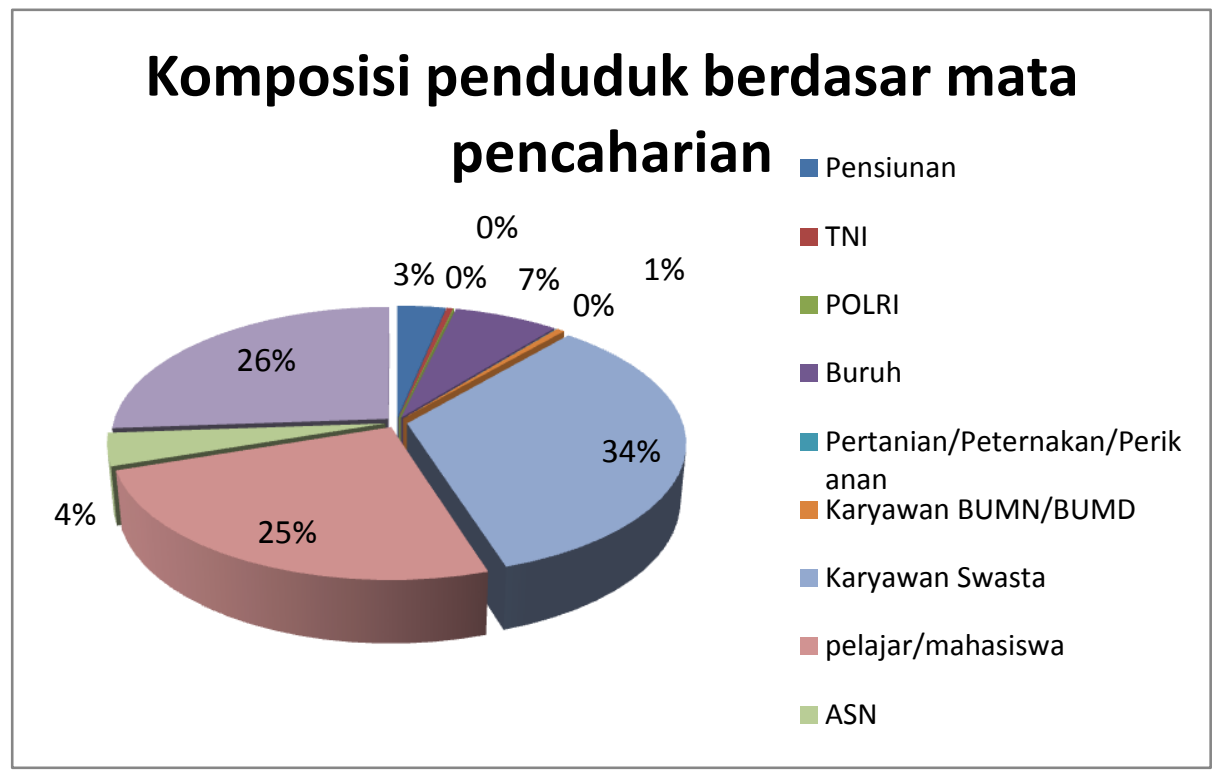

Gambar 2. Komposisi penduduk Cokrodiningratan berdasar mata pencaharian

Komposisi penduduk Cokrodiningratan berdasar jenjang pendidikan yaitu tidak sekolah sebanyak 951 jiwa, belum tamat SD sebanyak 908 jiwa, tamat SD sebanyak 1003 jiwa, SMP sebanyak 1121 jiwa, SMA sebanyak 3064 jiwa, Diploma I/II sebanyak 82 jiwa, Akademi/D3/S.Muda sebanyak 442 jiwa, D4/S1 sebanyak 603 jiwa, S2 sebanyak 110 jiwa, dan S3 sebanyak 8 jiwa. Komposisi penduduk berdasar jenjang pendidikan tersaji pada Gambar 3.

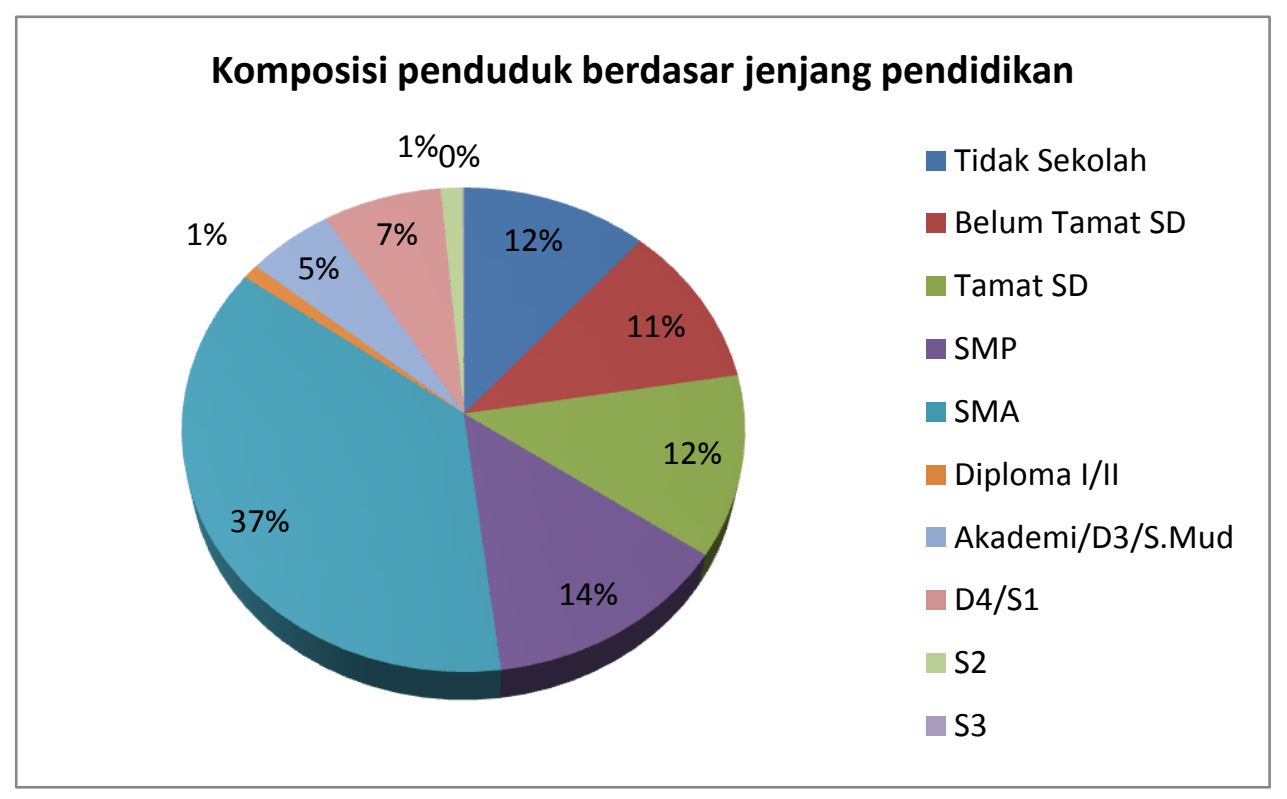

Gambar 3. Komposisi penduduk Cokrodiningratan berdasar jenjang pendidikan 
Komposisi penduduk Cokrodiningratan berdasar usia yaitu kategori usia 0-14 tahun sebanyak 1860 jiwa, kategori usia 15-64 tahun sebanyak 6345 jiwa, dan kategori usia lebih dari 64 tahun sebanyak 724 jiwa. Komposisi penduduk berdasar usia tersaji pada gambar 4.

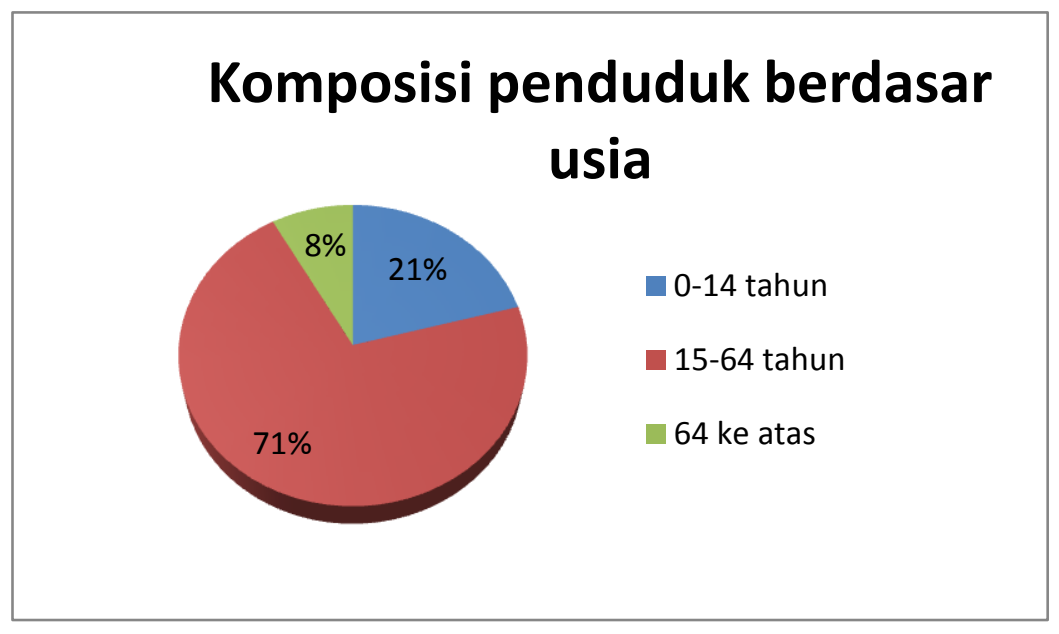

Gambar 4. Komposisi penduduk berdasar usia

Beberapa permasalahan yang ditemukan di Cokrodiningratan adalah: 1) aktivitas masyarakat yang terbatas dan belum adanya jadwal rutin berolahraga; 2) masyarakat Cokrodiningratan belum pernah mendapat pelatihan tentang lilin aroma terapi dan balsem ; 3) pemanfaatan dan pengelolaan lahan kosong belum maksimal; 4) pengetahuan masyarakat terhadap obat belum optimal. Dari pemaparan permasalahan yang ada di Cokrodiningratan tersebut, maka melalui kegiatan KKN UAD periode 57 beserta dosen pebimbing lapangan (DPL), melakukan beberapa program sebagai solusi dari permasalahan tersebut. Program kerja tersebut yakni: penghijauan; pengadaan tanaman TOGA; pembuatan balsem; pelatihan pembuatan lilin aroma terapi; penyelenggaraan senam dan jalan sehat; penyelenggaraan kerjabakti lingkungan bersih; pelatihan apoteker kecil; konseling obat dan pemeriksaan kesehatan gratis.

Berhasil atau tidaknya suatu program di masyarakat sangat dipengaruhi peran serta masyarakat. Peran serta masyarakat merupakan kesediaan masyarakat dalam membantu berhasilnya program menuju masyarakat sehat ini sesuai dengan kemampuan setiap orang tanpa mengorbankan kepentingan diri sendiri. Tanpa adanya peran serta masyarakat semua program yang direncanakan tidak akan mencapai hasil sesuai harapan. Menurut Munandar (2001) "Kreativitas dan inovasi masyarakat mempunyai peran yang sangat besar untuk meningkatkan kesejahteraan masyarakat." 
Berdasarkan permasalahan tersebut, maka ditetapkan tujuan program KKN UAD kali ini adalah memberdayakan masyarakat Cokrodiningratan dalam program Masyarakat Sehat.

\section{METODE}

Untuk mencapai tujuan yang diharapkan, program KKN UAD di Cokrodiningratan, dilakukan dengan memberdayakan masyarakat melalui pendidikan masyarakat, difusi ilmu pengetahuan dan teknologi, serta praktek langsung/pendamingan. Waktu pelaksanaan program dart tanggal 20 Oktober-20 Desember 2017. Ringkasan metode pelaksanaan beserta jam kerja efektif mahasiswa (JKEM) tersaji pada Tabel I.

Tabel 1. Metode, Kegiatan dan JKEM

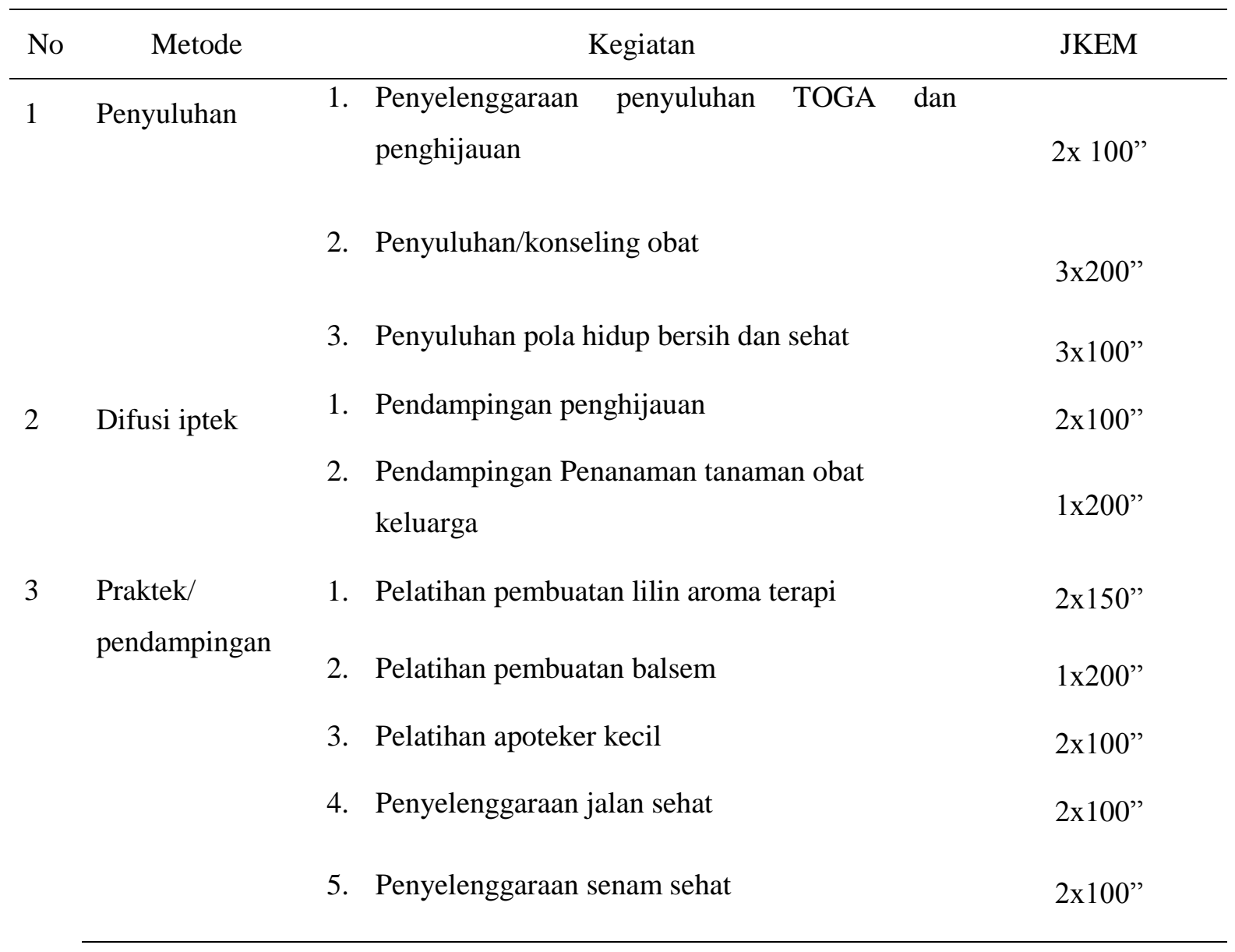

\section{HASIL, PEMBAHASAN, DAN DAMPAK}

Gambar aktivitas mahasiswa KKN UAD didampingi DPL bersama masyarakat Cokrodiningratan dalam program Masyarakat Sehat tersaji pada Gambar 5. 


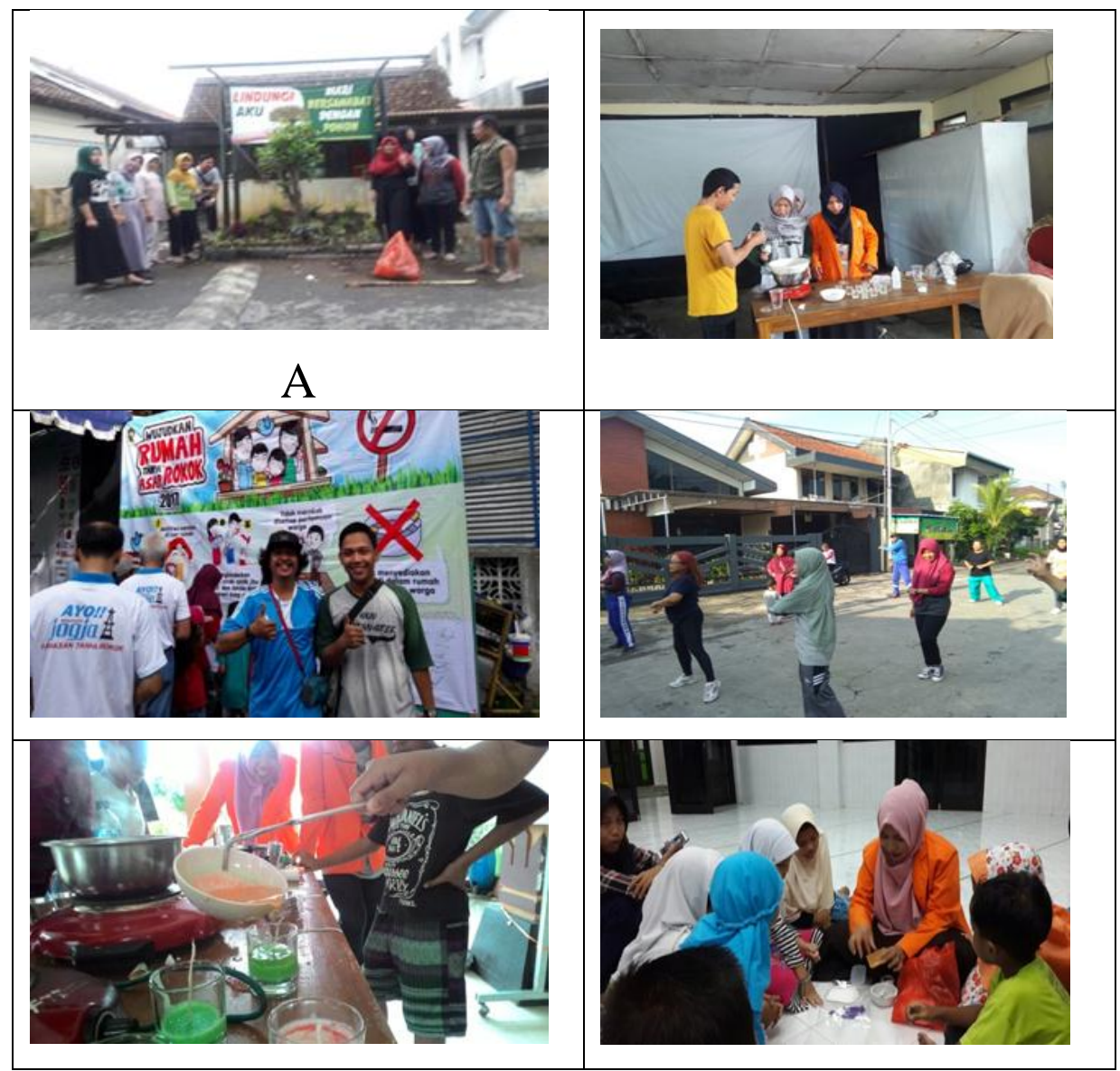

Gambar 5. A) Penghijauan dan TOGA, B) Pelatihan pembuatan balsam C) Jalan sehat D) Senam sehat E) Pembuatan lilin aroma terapi, F) Pelatihan Apoteker cilik

Penduduk yang sehat akan mampu bekerja produktif sehingga dapat meningkatkan pendapatan keluarga (Hapsari, 2009). Dari gambar 5 terlihat program KKN UAD di Cokrodiningratan dapat terlaksana dengan partisipasi masyarakat dengan kata lain dapat memperdayakan masyarakat dalam program-program yang telah direncanakan.

Dampak dari kegiatan KKN ini adalah: 1) tercipta kesadaran masyarakat sasaran tentang menanam tanaman obat keluarga; 2) peningkatan ketrampilan masyarakat dalam membuat lilin aroma terapi dan balsem; 3) terciptanya kegiatan olah raga masyarakat secara rutin; 4) peningkatan pengetahuan masyarakat tentang obat ; 5) memperoleh layanan pengobatan gratis, 6) peningkatan kegiatan kebersihan lingkungan (kerja bakti) 
Kegiatan dengan program Masyarakat Sehat ini, jika dilihat dari partisipasi masyarakat dalam keikutsertaan kegiatan dapat dikatakan sukses, dikarenakan masyarakat memiliki antusias yang tinggi dalam berpartisipasi. Selain itu, terlihat dalam proses kegiatan terdapat masyarakat yang mendesi sendiri. Kegiatan program Menuju Masyarakat sangat membantu masyarakat Cokrodiningratan dalam meningkatkan pengetahuan sekaligus praktik langsung, sehingga manfaat dari program ini dapat diimplementasikan di masyarakat Cokrodiningratan.

\section{SIMPULAN}

Program Masyarakat Sehat yang diselenggarakan mahasiswa KKN UAD mampu memberdayakan masyarakat Cokrodiningratan. Kegiatan berhasil dan didukung penuh oleh masyarakat.

\section{DAFTAR PUSTAKA}

Munandar, U. 2001. Pengalaman Hidup 10 Tokoh Kreativitas Indonesia: Mengembangkan Kreativitas. Jakarta : Yayasan Pustaka Obor Indonesia. [diakses tanggal 26 Desember 2017, pukul 11.02].

Hapsari, D. 2009. Pengaruh Lingkungan Sehat dan Perilaku Hidup Sehat terhadap Status Kesehatan. Buletin Penelitian Kesehatan, Hal : 40. 
